\title{
QUEEN'S
UNIVERSITY
BELFAST
}

\section{Psychometric evaluation of the Student Authorship Questionnaire: a confirmatory factor analysis approach}

Ballantine, J., Guo, X., \& Larres, P. (2015). Psychometric evaluation of the Student Authorship Questionnaire: a confirmatory factor analysis approach. Studies in Higher Education, 40(4), 596-609.

https://doi.org/10.1080/03075079.2013.835910

\section{Published in:}

Studies in Higher Education

\section{Document Version:}

Peer reviewed version

Queen's University Belfast - Research Portal:

Link to publication record in Queen's University Belfast Research Portal

\author{
Publisher rights \\ (C) 2013 Society for Research into Higher Education \\ The Version of Record of this manuscript has been published \\ and is available in Studies in Higher Education Volume 40, Issue 4, 2013 \\ http://www.tandfonline.com/doi/abs/10.1080/03075079.2013.835910
}

\section{General rights}

Copyright for the publications made accessible via the Queen's University Belfast Research Portal is retained by the author(s) and / or other copyright owners and it is a condition of accessing these publications that users recognise and abide by the legal requirements associated with these rights.

Take down policy

The Research Portal is Queen's institutional repository that provides access to Queen's research output. Every effort has been made to ensure that content in the Research Portal does not infringe any person's rights, or applicable UK laws. If you discover content in the Research Portal that you believe breaches copyright or violates any law, please contact openaccess@qub.ac.uk. 
Psychometric evaluation of the Student Authorship Questionnaire: a confirmatory factor analysis approach

Joan Ballantine*, Xin Guo** and Patricia Larres***

*Department of Accounting, Room 03C23, University of Ulster, Jordanstown campus, Shore Road, Newtownabbey, Co. Antrim, BT37 0QB

**University of the West of Scotland, UK

***Queen’s University Management School, Queen’s University, Belfast Belfast, BT7 1NN

* Address for correspondence: Joan A. Ballantine, Professor of Accounting, Department of Accounting, Room 03C23, University of Ulster, Jordanstown campus, Shore Road, Newtownabbey, Co. Antrim, BT37 0QB, Telephone: +44 (0)28 90366204 , Fax: +44 (0)28 90368502, e-mail joan.ballantine@ulster.ac.uk 
Abstract

This research provides new insights into the measurement of students'authorial identity and its potential for minimising the incidence of unintentional plagiarism by providing evidence about the psychometric properties of the Student Authorship Questionnaire (SAQ) (Pittam et al., 2009). Exploratory and confirmatory factor analysis (EFA and CFA) are employed to investigate the measurement properties of the scales which comprise the SAQ using data collected from accounting students. The results provide limited psychometric support in favour of the factorial structure of the SAQ and raise a number of questions regarding the instrument's robustness and generalisability across disciplines. An alternative model derived from the EFA is found to outperform the SAQ model with regard to its psychometric properties. Explanations for these findings are proffered and avenues for future research suggested.

Keywords: $\quad$ Authorial Identity, Unintentional Plagiarism, SAQ, Discipline, Voice 


\section{Introduction}

Plagiarism, derived from the Latin word plagium meaning 'kidnapping', is defined as 'the practice of taking someone else's work or ideas and passing them off as one's own' (Oxford English Dictionary). While plagiarism is not illegal in itself, it is viewed as unethical insofar as it constitutes intellectual property theft. Furthermore, within academia it is seen as a practice which hinders the creation of new ideas, reduces originality and undermines the academic integrity and reputation of the institution associated with the offence. However, not everyone views plagiarism with the same degree of seriousness. In particular, students may often regard it as irrelevant and inconsequential (Ashworth, Bannister, and Thorne 1997). The trivialization of plagiarism by some students may result from confusion as to what actually constitutes plagiarism. In other words, when does referring to academic material become plagiarism? Academics actively encourage the practice of building on and developing others' ideas with attribution and do not focus on the fact that their writing is not always 'wholly' original in its source. Students, on the other hand, often labour under the misunderstanding that what they write needs to originate in their own thoughts and be completely novel if they are to avoid plagiarism (Ivanič 1997). To this end, the problem which students have in identifying plagiarism may reside in the awareness which they, vis-à-vis academics, have of themselves as authors and the textual identity which they create when they write. 
The issue of establishing an appropriate authorial identity among students to minimise the incidence of plagiarism has been addressed by a number of studies to date (Abasi, Akbari, and Graves 2006; Pittam et al. 2009). In particular, Pittam et al. (2009) have focussed on the importance of promoting greater authorial identity among students to help prevent unintentional plagiarism. This type of plagiarism, as the name suggests, is committed unwittingly by a student when he or she, maybe through ignorance, does not follow accepted conventions or practices when drawing on academic materials. Such practices include directly quoting from another author's work, the use and acknowledgement of others' ideas and the compilation of reference lists (see for example, Park 2003; Wells 1993). Authorial identity, Pittam et al. (2009) argue, is strongly linked with unintentional plagiarism in that, if the former is poorly developed, then the latter is more likely to occur.

To gain a better understanding of students' perceptions of authorship and academic writing and thereby inform interventions designed to prevent unintentional plagiarism, Pittam et al. (2009) developed the Student Authorship Questionnaire (SAQ). Given the potential that developing one's authorial identity has for minimising plagiarism, the current study attempts to build on this limited work and provide greater insights into this area of research. In so doing, the researchers are also responding to a call from Pittam et al. (2009) to provide more evidence about the psychometric properties of the SAQ and extend the concept of authorial identity beyond the discipline of psychology. This is achieved by applying both exploratory and confirmatory factor analysis (EFA 
and CFA) to investigate the measurement properties of the scales which comprise the SAQ using data collected from a large sample of accounting students. The results provide limited psychometric support for the factorial structure reported by Pittam et al. (2009). Accordingly, an alternative model derived from the EFA in the current study was found to outperform the SAQ model with regard to its psychometric properties.

The remainder of the paper is structured as follows. First, a review of the relevant literature is presented. Secondly, the research methodology applied to the study is set out. Thirdly, the results of the tests of the EFA and CFA are presented, analysed and discussed. Finally, conclusions are drawn and further work identified.

\section{Literature review}

Authorial identity is the sense which writers have of themselves as authors and the textual identity which they construct in their writing (Pittam et al. 2009). Kinder and Elander (2012) argue that a strong authorial identity is synonymous with confidence in writing and an understanding of how to present ideas and arguments as one’s own. This identity, within the context of academic writing, serves to convey not only disciplinary content but also provides a sense of the author's distinctive 'voice' Hyland (2002). The concept of 'voice', which has its origins in the work of Bakhtin (1986), is described by Matsuda (2001) as 'the amalgamative effect of the use of discursive and non-discursive features that language users choose, deliberately or otherwise, from 
socially available, yet ever changing repertoires' (40). To establish a strong authorial identity academic writers should incorporate their 'voice' into their prose thereby demonstrating their presence within their text while paying attention to the conventions and protocols of their discourse community ${ }^{1}$.

When considering the influence of one's discourse community and how the presence of authorial identity varies across disciplines, a number of academic writers (Hyland 2001, 2002; Harwood 2005a, 2005b) have applied Biglan’s (1973a, 1973b) typology of academic subject areas ${ }^{2}$. For example, Hyland (2002) argues that more explicit authorial identity exists in the soft-knowledge disciplines whereas the tendency in hardknowledge disciplines is towards 'author evacuated prose' (Geertz 1988, 9). In particular, Hyland (2001) considers the issue of self-mention in academic prose by drawing on a corpus of research articles from a range of disciplines spread across Biglan’s (1973a, 1973b) hard/soft, pure/applied and life/non-life system dimensions. Focussing on the use of first person pronouns in academic prose across subject areas, Hyland (2001) concedes that not all disciplines sanction the same degree of authorial presence. However, he goes on to point out that 'disciplinary conventions are enabling rather than deterministic, and typical patterns of self-mention only provide

\footnotetext{
${ }^{1}$ Swales (1990) describes a discourse community as a group which uses communication to achieve its common goals.

${ }^{2}$ Drawing on the judgements of academic faculty members and subsequent analysis, Biglan (1973b) used multidimensional scaling to develop a taxonomy which classifies academic disciplines along three dimensions, namely [1]'the existence of a single paradigm (hard-soft) ... [2] concern with practical application (pure-applied) $\ldots$ and [3]concern with life systems' (207).
} 
broad perimeters of choice. In constructing their texts, writers also construct themselves, and self-reference represents the confidence to speak authoritatively rather than concealing authorship behind the impersonality options the genre provides' (Hyland 2001, 224).

While 'voice' or authorial identity has been extensively explored with regard to the cultural and institutional aspects of authorship (see for example, Howard 1995) and the analyses of discourses of writing, more recently the concept has been applied to understanding the causes of unintentional plagiarism. Abasi, Akbari, and Graves (2006), researching among students for whom English was a second language, argue that unintentional plagiarism could more usefully be considered as 'the result of students' failure to represent themselves as writers who should make a novel contribution, however modest it might be, through critically engaging with sources' (114). Moreover, less experienced students in Abasi, Akbari, and Graves's study viewed published work as a source of impersonal truths to be reproduced at will. Such an epistemological perspective on published work, Abasi, Akbari, and Graves (2006) argue, contrasts markedly with that of professional academic writers who appreciate the input of 'human agency' into the 'construction of knowledge' (Latour and Woolgar 1979). Therefore, the key factor explaining the difference in epistemological perspectives between students and academics is their respective appreciation of authorial identity. The conclusion to be drawn from Abasi, Akbari, and Graves’s 
(2006) findings is that a poorly developed authorial identity may result in unintentional plagiarism.

Drawing on the work of Abasi, Akbari, and Graves (2006), a small number of UKbased studies (Pittam et al. 2009; Elander et al. 2010; and Kinder and Elander 2012) have developed further the relationship between authorial identity and unintentional plagiarism. Pittam et al. (2009) explored undergraduate and postgraduate psychology students' perceptions of authorial identity in order to inform interventions to reduce unintentional plagiarism and improve students' authorial identity. Their study adopted a mixed methodological approach which consisted of the use of focus groups and the development of a research instrument. Their analysis of focus group discussions with nineteen psychology students identified a number of key findings or themes. First, students reported a greater sense of authorial identity when engaging in individualized project work which permitted greater choice over the subject matter rather than writing an essay where the topic of interest is given. Secondly, 'students also experienced tensions between what they perceived as required for genuine authorship [author] ... and the style of writing required in academic assignments [editor]' (Pittam et al. 2009, p159). Thirdly, fear and uncertainty regarding the boundaries between paraphrasing, quoting and plagiarising were reported and found to be associated with underdeveloped authorial identities. Finally, participants in the focus groups identified both time constraints and second language issues as obstacles to developing a strong authorial identity. Drawing on evidence related to these four 
themes and a review of the relevant literature, Pittam et al. (2009) designed a research instrument, the Student Authorship Questionnaire (SAQ) to measure attitudes towards authorial identity in academic writing. Using 318 responses from undergraduate and postgraduate psychology students across three UK universities, Pittam et al. (2009) conducted an exploratory factor analysis which identified six factors, three relating to authorial identity (confidence in writing, understanding authorship and knowledge to avoid plagiarism) and three associated with approaches to writing (pragmatic, top-down and bottom-up approaches to writing). The findings from both the focus groups and the questionnaire study showed considerable scope for improving students' authorial identity. Pittam et al. (2009) suggested that this could be achieved by way of instruction to students on the technical aspects of citation, referencing and paraphrasing and would be more effective if combined with measures which encourage and develop students’ authorial identity.

Building on Pittam et al.'s (2009) work, Elander et al. (2010) report on a study which investigated the results of adopting an intervention to improve authorial identity among psychology students at three UK universities. The intervention consisted of advice and instruction on authorship including high profile cases of suspected or alleged plagiarism. The success of the intervention was tested at three levels, namely a before and after measure of beliefs and attitudes using the SAQ, student focus groups and feedback from academic staff at the participating institutions. The results of the before and after study found that the overwhelming majority of students believed that 
the intervention had helped them avoid unintentional plagiarism. Furthermore, feedback from the student focus groups suggested that the intervention was generally successful in terms of enhancing their understanding of what constitutes plagiarism. However, while feedback from academic staff also suggested a decrease in perceptions of incidences of plagiaristic behaviour following the intervention, these were not found to be statistically significant. Elander et al. (2010) concluded that the intervention had helped contribute to students' avoidance of unintentional plagiarism by adopting greater authorial roles in their academic writing.

Working in the same area of study, Kinder and Elander (2012) compared dyslexic and non-dyslexic students' authorial identity and approaches to learning. Using a sample of 62 UK undergraduate and postgraduate students from a variety of disciplines, Kinder and Elander (2012) gathered data by distributing a questionnaire which combined questions from the SAQ with those from Approaches and Study Skills Inventory for Students (ASSIST) developed by Tait, Entwistle, and McCune (1998). In addition, they carried out a series of semi-structured interviews with dyslexic students who had achieved high and low SAQ scores. With respect to the factors identified in Pittam et al. (2009), dyslexic students scored lower in confidence in writing, understanding authorship and strategic approaches to learning, and higher in surface approaches to learning, than their non-dyslexic counterparts.

While the studies referred to above have utilised the SAQ to explore authorial identity in the context of unintentional plagiarism within the discipline of psychology in 
particular, the psychometric properties of the scales of the research instrument have not been investigated and reported on. The current study addresses this gap in the literature and in so doing responds to a call from Pittam et al. (2009) for further investigation in this regard by using confirmatory factor analysis (CFA). Accordingly, greater insights into measurement for research in this area are provided.

\section{Method}

\section{Questionnaire Design}

The questionnaire ${ }^{3}$ used in the study consisted of two sections. Section one contained questions on demographic information including gender, the country where preuniversity education had been obtained and students' age. Section two consisted of eighteen statements as set out in the SAQ developed by Pittam et al. (2009) to elicit perceptions of authorial identity and approaches to writing. The first seventeen statements require respondents to indicate their acceptance using a five-point Likert scale anchored with 'strongly agree' and 'strongly disagree'. Sample statements include: 'I would never be accused of plagiarism' (a positive authorial identity statement); 'When writing about an assignment I begin by thinking about what I want to say, and then look for evidence relating to that' (a positive authorial identity statement); and 'I am afraid that what I write myself about [my discipline] will look weak and unimpressive' (a negative authorial identity statement). The eighteenth statement requires students to indicate the proportion of their written assignments that

\footnotetext{
3 A copy of the questionnaire is available on request from the authors.
} 
consists of quotations or materials taken directly from books, journals or the internet using the following scale: $0-20 \%, 21-40 \%, 41-60 \%, 61-80 \%$ and $81-100 \%$. Ethical approval for the study was obtained from the research ethics committees of the universities involved in the study.

\section{Data Collection}

Questionnaires were distributed to accounting undergraduate students at three Irish universities towards the end of the academic year. For purposes of clarification, the aim of the study was indicated on the front cover of the questionnaire. Moreover, the nature of the study was reinforced by the academic member of staff responsible for distribution together with guidance on completing the research instrument. In order to encourage honest responses to a relatively sensitive subject, students were reassured that their anonymity would be observed and that the results of the study would be used for research purposes only with no individual responses being reported. Students were given approximately twenty minutes to complete the questionnaire. Usable questionnaires were obtained for 588 students, representing 217 (36.9\%) from University One, 184 (31.3\%) from University Two and 187 (31.8\%) from University Three. 
The three universities involved in the study operate a number of common initiatives and policies to aid the development of authorial identity and thereby minimise plagiarism. First, students commencing their studies are required, in their first semester, to attend a series of instructional sessions aimed at developing authorial identity skills. Rather like the 'freshman composition class', popular in the US as a core curriculum writing course, the focus of the instructional sessions at the three universities is the development of students' authorial identity within their discipline with respect to academic writing and appropriate referencing. However, these instructional sessions are not likely to be as comprehensive as a 'freshman composition class' in that the latter normally extends over a longer period of time. The instructional sessions also address various aspects of intentional plagiarism including: defining plagiarism; outlining procedures for submitting written work to avoid plagiarism; reporting cases of plagiarism; and detailing procedures for dealing with plagiarism. Secondly, various issues related to intentional plagiarism are communicated via a student handbook which is available to students at all levels of their degree programme. The handbook serves as the primary point of reference for students with respect to understanding what constitutes intentional plagiarism and sets out institutional policies and procedures around intentional plagiarism. Finally, on a less formal basis, accounting academics provide on-going instruction and advice to their students throughout their degree programme to reinforce aspects related to authorial identity and the avoidance of intentional and unintentional plagiarism. Guidance in this respect is provided in the context of the requirements for continuous assessment and examinations, 
insofar as they require the application of academic writing. For example, the importance of developing one's ideas and arguments first and then looking for academic sources to back these up are discussed by teaching staff.

\section{Statistical analysis}

The statistical analysis proceeded in four parts. First, to estimate internal consistency reliability, Cronbach's alpha coefficients were calculated for scores yielded by the SAQ inventory for each of the six factors reported by Pittam et al. (2009). Secondly, correlation coefficients were calculated to examine any statistically significant relationships among the six factors identified by Pittam et al. (2009). Thirdly, an exploratory factor analysis (EFA) using principal components analysis was undertaken to explore the underlying structure of the SAQ inventory. Three issues were considered when using EFA: (i) the extraction method; (ii) the number of factors to be extracted; and (iii) the rotation of the solution. Specifically, principal component analysis was chosen as the extraction method since it yields component scores that have the same correlation coefficients as the rotated factors and component analysis does not unduly capitalise on sampling error as the price for estimating measuring error (Thompson and Daniel 1996); a scree test (Cattell 1978) was used to identify the number of factors to be extracted as it is more accurate than the eigenvalues-greater-than-one criterion when both are tested on artificially generated sample data (Zwick and Velicer 1982); and the factor solution was obliquely rotated using oblimin rotation to improve the interpretability of the final solution as this rotation type 'allows correlated factors 
instead of maintaining independence between the rotated factors’' (Hair et al. 2010, 115). Fourthly, the SAQ model was tested by confirmatory factor analysis (CFA) via AMOS to assess model fit to the data (Arbuckle 2006). AMOS is a statistical program which performs structural equation modelling, a form of multivariate analysis. To evaluate the fit of the measurement models, comparative fit index (CFI) was used together with the root mean square error of approximation (RMSEA) in tandem with the standardized root mean square residual (SRMR) as recommended by Hu and Bentler (1999) and MacCallum and Austin (2000). Statistical significance testing was also undertaken ( $\alpha$ $=.05)$.

\section{Findings}

\section{Reliability}

The internal consistency reliability of scores yielded by the six factors of Pittam et al.'s (2009) original SAQ model is presented in Table 1. Specifically, internal consistency reliability was acceptable for confidence in writing $(\alpha=0.63)$, understanding authorship ( $\alpha=0.71)$ and knowledge to avoid plagiarism $(\alpha=0.64)$, moderate for pragmatic approach to writing ( $\alpha=0.53$ ), and unsatisfactory for top-down approach to writing ( $\alpha$ $=0.19)$ and bottom up approach $(\alpha=0.29)^{4}$ (Nunnally 1978; Hair et al. 1998, 2003).

\footnotetext{
${ }^{4}$ An explanation for the two unsatisfactory alpha coefficients is that the associated factors comprise too few items (Hinkin 1995).
} 
The alpha coefficients calculated were comparable with those reported by Pittam et al. $(2009)^{5}$.

\section{Table 1 here}

\section{Correlations between all factors}

The correlation coefficients between the six factors identified in Pittam et al.’s (2009) SAQ model are also reported in Table 1 . Five of the six factors were positively intercorrelated at a significant level of at least 0.05 , one exception being bottom-up approach to writing: that is, it was not correlated with confidence in writing, understanding authorship and knowledge to avoid plagiarism; it has a low correlation coefficient with top-down approach $(r=0.10)$ and a negative one with pragmatic approach $(r=-0.20)$. This was an interesting finding as it suggested that better psychometric properties might be obtained by removing certain items (for example, items in bottom-up approach) or reconsidering the factorial structure of the inventory.

\section{EFA}

EFA was used to simplify the complex sets of data collected from the SAQ inventory and explore the possible structure of the inventory. Rotated factor loadings and reliability coefficients are provided in Table 2. Principal component analysis using

\footnotetext{
5In Pittam et al.'s (2009) study Cronbach's alpha coefficients were only reported for the factors with more than two items: 0.69 for confidence in writing, 0.62 for knowledge to avoid plagiarism and 0.46 for pragmatic approach to writing.
} 
oblimin rotation identified three factors. The first factor included five items, two from the understanding authorship factor (items 1 and 2) in Pittam et al.’s (2009) model and three from their factor entitled knowledge to avoid plagiarism (items 3, 4 and 8). A possible explanation for the items from understanding authorship and knowledge to avoid plagiarism being loaded together in this way is that the three institutions involved in the current study include in their degree programmes instructional sessions to improve students' understanding of authorial identity and reduce the incidence of plagiarism. The second factor included four items, two from Pittam et al.'s (2009) confidence in writing factor (items 6 and 16) and two from their pragmatic approach to writing (items 10 and 11). The third factor included three items, one from Pittam et al.'s (2009) confidence in writing factor (item 15), one from their top-down approach to writing (item 14) and one from their pragmatic approach to writing (item 17). The three factors found in the current study accounted for $22.6 \%$ (factor 1), 11.2\% (factor 2) and 8.0\% (factor 3) of the total variance respectively. Six items from Pittam et al.’s (2009) SAQ (items 5, 7, 9, 12, 13 and 18) were discarded in the EFA due to their poor factor loadings (i.e. < .5). Collectively, the EFA of data collected from the sample in the current study failed to replicate the factorial structure reported by Pittam et al. (2009). However, the EFA results could be usefully employed for constructing alternative models for comparison purposes in the subsequent confirmatory factor analysis (CFA).

Table 2 here 


\section{CFA}

CFA was used to assess model fit to the data. For comparison purposes, CFA was conducted on four different models (See Table 3, Panel A). The first model (Model I) to be tested was the original SAQ model, containing 18 items pertaining to six factors (Pittam et al. 2009). However, Model I did not provide an acceptable fit to the data ( $\chi 2$ $(120)=476.315 ;$ CFI $=.787 ;$ RMSEA $=.071 ;$ SRMR $=.067) .6$ The second model (Model II) was a two-factor model also comprising Pittam et al.’s (2009) 18 items. The first factor of Model II was made up of the three authorial identity factors from Pittam et al. (2009) (i.e. confidence in writing, understanding authorship and knowledge to avoid plagiarism) while the second factor of Model II contained Pittam et al.’s (2009) three approaches to writing factors (i.e. top-down, bottom-up and pragmatic approaches to writing). Again, Model II failed to provide an acceptable fit to the data ( $\chi 2$ (134) $=$ 786.355; CFI $=.609 ;$ RMSEA $=.091 ;$ SRMR $=.087$ ). The third model (Model III), established in the current study for comparison purposes, was a one-factor model with all of Pittam et al.'s (2009) 18 items considered as belonging to one factor. Model III produced the worst model fit of all four models tested $\left(\chi^{2}(135)=839.214 ; \mathrm{CFI}=.578\right.$; RMSEA $=.094 ;$ SRMR $=.085$ ). Finally, the fourth model (Model IV) tested was derived from the EFA results in the current study, with 12 items pertaining to three factors. Model IV provided a highly satisfactory fit to the data $\left(\chi^{2}(47)=136.643\right.$; CFI $=.924 ; \mathrm{RMSEA}=.057 ; \mathrm{SRMR}=.051)$.

In summary, Model IV (the revised model) is preferred on the grounds of better psychometric properties. This revision provides a briefer 12 item model with a simpler 
three factor structure when compared to Pittam et al.'s (2009) SAQ model. The three factors of the revised model are labelled understanding authorship and plagiarism, lack of confidence in writing and authorial approach to writing. These three factors were correlated at a significance level of .001, indicating that the students in the current study were of the opinion that all the factors were highly associated and part of an overall construct of authorial identity (see Table 3, Panel B). Specifically, lack of confidence in writing was negatively related to understanding authorship and plagiarism $(r=-.27)$ and authorial approach to writing $(\mathrm{r}=-.53)$; understanding authorship and plagiarism was positively associated with authorial approach to writing $(\mathrm{r}=.48)$. Internal consistency reliability was estimated for each of the three factors of Model IV using Cronbach's alpha coefficients. These were .71 for understanding authorship and plagiarism, .61 for lack of confidence in writing and .53 for authorial approach to writing, suggesting moderate to satisfactory internal consistency reliability. Collectively, the results indicate that the revised model (see Figure 1) possesses better psychometric properties than the SAQ model developed by Pittam et al. (2009). Finally, for the purpose of facilitating comparisons of the results of the current study with future studies in alternative disciplines and settings, Table 3 also reports the means and standard deviations for each of the three factors of the revised model. The scoring method used to determine the means reported is that of a simple mean which accords equal importance to each of the items within each factor. This approach is consistent with previous studies in this area (Pittam et al. 2009; Elander et al. 2010). 
Figure 1 here

\section{Discussion and conclusion}

The revised model reported in the current study consisted of three factors, namely factor one, understanding authorship and plagiarism, factor two, lack of confidence in writing and factor three, authorial approach to writing. Whilst these results reflect an early stage of development, nonetheless they warrant further explanation and comparison with the findings from the study by Pittam et al (2009). Of the three factors found in the current study, only factor one, understanding authorship and plagiarism, provides some degree of comparison with the item composition of Pittam et al.’s (2009) study. Understanding authorship and plagiarism comprises five items (i.e. 1, 2, 3, 4 and 8) which are split across two factors in Pittam et al.'s (2009) model, namely items 1 and 2 are to be found in understanding authorship, while items 3, 4 and 8 are included in knowledge to avoid plagiarism. A possible explanation for the similarity in factor loadings between the two studies could rest with the disciplinary background from which the respondents in the surveys are drawn. The students making up Pittam et al.'s study are from a psychology background and those involved in the current study are from accounting. Psychology and accounting both fall within the broader quadrant of soft knowledge identified as the first dimension of discipline classification by Biglan 
(1973a, 1973b). The significance of this classification is that authorial development is more explicit in a soft knowledge discipline than is the case in a hard knowledge area such as engineering where writing is more objective and the author less likely to take ownership of his/her work. Therefore, it would appear that the students in both studies, despite coming from different backgrounds, demonstrate a degree of authorial awareness. The results of the CFA in the current study advance our understanding of the SAQ model in that its two factors (i.e. understanding authorship and knowledge to avoid plagiarism) are highly correlated and converge into one homogeneous factor in the revised model. In other words, the CFA carried out in the current study provides empirical evidence to confirm what Abasi, Akbari and Graves (2006) and Pittam et al. (2009) suggested in their respective studies, namely that a strong authorial identity is linked to an awareness of avoiding plagiarism. The finding therefore would appear to support the proposition put forward by Abasi, Akbari and Graves (2006) and Pittam et al. (2009) that plagiarism should not be viewed solely as a moral transgression arising purely out of dishonesty, but rather as an act which can be avoided through learning, developing writing skills and gaining authorial confidence.

However, notwithstanding the degree of convergence discussed above, the factor loadings reported elsewhere differ quite significantly between the two studies. For example, negatively phrased items such as 'I find it difficult to express my subject in my own words' are all loaded into one factor in the current study, i.e. factor 2, lack of confidence in writing, whereas these negative items are loaded across a number of 
factors in Pittam et al.'s (2009) study. This concentration of negative items into one factor appears to establish some doubt among the respondents to the current study regarding their ability to write specifically about the discipline of accounting. This apparent lack of confidence regarding one's subject area may be explained by the pureapplied dimension of Biglan’s (1973a, 1973b) topology which finds accounting and psychology at opposite ends of the scale. Accounting is an applied discipline, yet the majority of accounting undergraduates will have had limited or no practical experience in the field (Garcia 2010). Accordingly, this inexperience may lead to a concern among accounting students that their prose will appear weak and unimpressive, creating a reticence to personalise their writing. This type of dilemma may not exist to the same degree in a pure discipline such as psychology which lends itself more to creativity in thinking and fluency of expression (Lindblom-Ylänne et al. 2006).

The third factor identified in the current study, labelled authorial approach to writing, contained three positively phrased items. The factor loadings with respect to authorial approach to writing are markedly different from those reported by Pittam et al. (2009), who identified eight approaches to writing items loaded into three factors, namely pragmatic, top-down and bottom-up approach to writing. However, the findings in the current study with respect to authorial approach to writing have some parallels with those reported by Lavelle (1993) in her elaborative approach to writing. The elaborative approach to writing is characterized by 'a search for personal meaning, self-investment, and by viewing writing as symbolic, a deep personal investment' (Lavelle and Zuercher 
2001, 376) where 'voice', among other things, is used as a strategy (Lavelle and Guarino 2003). Thus, notwithstanding a lack of confidence in their ability to write with fluency in their discipline, as identified in factor 2, it would appear that students in the current study are aware of the importance of personalising their work and providing a sense of the author's distinctive 'voice'. It is anticipated that this realisation will assist them in steering a path away from engaging in unintentional plagiarism.

Pittam et al.’s (2009) development of the SAQ represents a significant advancement in our understanding of the concept of authorial identity and its impact on unintentional plagiarism. The majority (i.e. 12 items) of the 18 items reported in Pittam et al.’s (2009) SAQ appear in the revised model presented in the current paper. This would suggest that the SAQ inventory succeeds in capturing some aspects of authorial identity. However, notwithstanding this degree of convergence, the current study was unable to confirm the factorial structure of Pittam et al.'s (2009) SAQ. Rather, the results of the CFA suggest that the SAQ can best be considered as having three factors, namely understanding authorship and plagiarism, lack of confidence in writing and authorial approach to writing. In addition, issues regarding the SAQ's validity and reliability were raised. With respect to the former, data collected from the sample in the current study indicate that Pittam et al.'s (2009) SAQ model demonstrates unsatisfactory construct validity. Regarding the latter, whilst good reliability was reported for four of Pittam et al.'s (2009) factors, it was found to be poor for the remaining two. 
The current study raises a number of questions regarding the specificity and robustness of Pittam et al.’s (2009) SAQ. First, with respect to specificity, the findings reported here would lead one to question the generalisability of the SAQ and, in particular, its applicability to business-related disciplines. Indeed, the results of the CFA indicate that the factorial structure of the SAQ may vary according to discipline. To explore this concern further, future research could usefully examine the reliability and construct validity of the instrument in other disciplines. Secondly, with regard to the instrument's robustness, the obvious question to ask is whether all relevant aspects of a student's authorial identity have been sufficiently captured in the SAQ. To this end, future analysis could consider the impact of factors such as culture, gender and educational background on students' authorial identity in a multi-disciplinary context using a large item pool. Such an analysis may provide better measurement for research in this area. Additionally, future qualitative research involving, for example, student focus groups and in-depth interviews could usefully be employed to identify other items pertaining to students' authorial identity and thereby build on the innovative work begun by Pittam et al. (2009) and continue to develop and refine the SAQ for use across a range of disciplines, transcending culture, gender and educational background.

\section{References}

Abasi, A.R., N. Akbari, and B. Graves. 2006. Discourse appropriation, construction of identities, and the complex issue of plagiarism: ESL students writing in graduate school. Journal of Second Language Writing 15, no. 2:102-117. 
Arbuckle, J. L. 2006. Amos 7.0 User's Guide. Chicago: SPSS.

Ashworth, P., P. Bannister, and P. Thorne. 1997. Guilty in whose eyes? University students' perceptions of cheating and plagiarism in academic work and assessment. Studies in Higher Education 22, no. 2: 187-203.

Bakhtin, M.M. 1986. Speech Genres and Other Late Essays. Translated by McGee, V.W. Austin, Tx: University of Texas Press.

Biglan, A. 1973a. The Characteristics of Subject Matter in Different Academic Areas. Journal of Applied Psychology 57, no. 3: 195-203.

Biglan, A. 1973b. Relationships between subject matter characteristics and the structure and output of university departments. Journal of Applied Psychology 57, no. 3: 204213.

Cattell, R.B. 1978. The Scientific Use of Factor Analysis in the Behavioural and Life Sciences. New York: Plenum Press.

Elander, J., G. Pittam, J. Lusher, P. Fox and N. Payne. 2010. Evaluation of an intervention to help students avoid unintentional plagiarism by improving their authorial identity. Assessment and Evaluation in Higher Education. 35, no. 2: 157-171.

Garcia, L. 2010. Accounting Students' Expectations and Transition Experiences of Supervised Work Experience. Accounting Education: an international journal 19, no. 1-2: 51-64. 
Geertz, C. 1988. Words and Lives: The Anthropologist as Author. Palo Alto, CA: Stanford University Press.

Hair, J.F., R.E. Anderson, R.L. Tatham, and W. Black. 1998. Multivariate Data Analysis. Englewood Cliffs, NJ: Prentice-Hall.

Hair, J.F., B. Babin, A.H. Money, and P. Samuel. 2003. Essentials of Business Research Method. New York, New York: John Wiley \& Sons, Inc., USA.

Harwood, N. 2005a. We do not seem to have a theory . . . The theory I present here attempts to fill this gap': inclusive and exclusive pronouns in academic writing. Applied Linguistics 26, no. 3: 243-375.

Harwood, N. 2005b. 'Nowhere has anyone attempted...In this article I aim to do just that' A corpus-based study of self-promotional I and We in academic writing across four disciplines. Journal of Pragmatics 37: 1207-1231.

Hinkin, T.R. 1995. A review of scale development practices in the study of organizations. Journal of Management 21, no. 5: 967-988.

Howard, R.M. 1995. Plagiarisms, authorships and the academic death penalty. College English 57, no. 7: 788-806.

Hu, L., and P.M. Bentler. 1999. Cut-off criteria for fit indices in covariance structure analysis: Conventional versus new alternatives. Structural Equation Modelling 6, no. 1: $1-55$

Hyland, K. 2001. Humble servants of the discipline? Self mention in research articles. English for Specific Purposes 20, no. 3: 207-226. 
Hyland, K. 2002. Authority and invisibility: authorial identity in academic writing. Journal of Pragmatics 34: 1091-1112.

Ivanič, R. 1997. Writing and Identity: The discoursal construction of identity in academic writing. Amsterdam: John Benjamins.

Kinder, J. and J. Elander. 2012. Dyslexia, authorial identity, and approaches to learning and writing: A mixed methods study. British Journal of Educational Psychology 82, no. 2: 289-307.

Latour, B., and S. Woolgar. 1979. Laboratory life: The social construction of scientific facts. Beverly Hills: CA: Sage.

Lavelle, E. 1993. Development and validation of an inventory to assess processes in college composition. British Journal of Educational Psychology 63: 489-499.

Lavelle, E. and A.J. Guarino. 2003. A Multidimensional Approach to Understanding College Writing Processes. Educational Psychology 23, no. 3: 295-305.

Lavelle, E. and N. Zuercher. 2001. The Writing Approaches of University Students. Higher Education 42, no. 3:373-391.

Lindblom-Ylänne, S., K. Trigwell, A. Nevgi, and P. Ashwin. 2006. How approaches to teaching are affected by discipline and teaching context. Studies in Higher Education. 31, no. 3: 285-298

Matsuda, P.K. 2001. Voice in Japanese written discourse: Implications for second language writing. Journal of Second Language Writing 10: 35-53 
MacCallum, R.C. and J.T. Austin. 2000. Applications of structural equation modeling in psychological research. Annual Review of Psychology 51:201-226.

Nunnally, J.C. 1978. Psychometric theory ( $2^{\text {nd }}$ ed.). New York: McGraw-Hill.

Park, C. 2003. In Other (People's) Words: Plagiarism by university students - literature and lessons. Assessment and Evaluation in Higher Education 28, no. 5: 471-488.

Pittam, G., J. Elander, J. Lusher, P. Fox, and N. Payne. 2009. Student beliefs and attitudes about authorial identity in academic writing. Studies in Higher Education 34, no. 2: 153-170.

Swales, J. M. 1990. Genre Analysis: English in Academic and Research Settings. Cambridge: Cambridge University Press.

Tait, H., N.J. Entwistle, and V. McCune. 1998. ASSIST: A reconceptualisation of the Approaches to Studying Inventory. In Improving students as learners, ed. C. Rust 262271. Oxford: Oxford Brookes University, Oxford Centre for Staff and Learning Development.

Thompson, B. and L.G. Daniel. 1996. Factor analytic evidence for the construct validity of scores: A historical overview and some guidelines. Educational and Psychological Measurement 56, no. 2: 197-208.

Wells, D. (1993). An account of the complex causes of unintentional plagiarism in college writing. WPA: Writing Program Administration, 16, no. 3: 59-67.

Zwick, W.R. and W.F. Velicer. 1982. Factors influencing four rules for determining the number of components to retain. Multivariate Behavioral Research 17: 253-269. 
Table 1:

Correlation matrix for overall sample $(N=588)$, internal consistency reliability estimates, means, and standard deviations

\begin{tabular}{llllllllll}
\hline Factor $^{6}$ & Alpha & Mean & $\begin{array}{l}\text { Std. } \\
\text { Dev. }\end{array}$ & I & II & III & IV & $V$ \\
\hline \hline I & Confidence in writing & 0.63 & 2.87 & 0.61 & & & & \\
II & Understanding authorship & 0.71 & 3.98 & 0.79 & $0.24^{* *}$ & & & & \\
III & Knowledge to avoid plagiarism & 0.64 & 3.89 & 0.68 & $0.34^{* *}$ & $0.42^{* *}$ & & & \\
IV & Top-down approach to writing & 0.19 & 3.66 & 0.65 & $0.22^{* *}$ & $0.19^{* *}$ & $0.31^{* *}$ & & \\
V & Bottom-up approach to writing & 0.29 & 3.51 & 0.72 & -0.04 & 0.07 & 0.04 & $0.10^{*}$ & - \\
VI & Pragmatic approach to writing & 0.53 & 2.82 & 0.60 & $0.40^{* *}$ & $0.16^{* *}$ & $0.23^{* *}$ & $0.15^{* *}$ & $0.20^{* *}$ \\
\hline
\end{tabular}

Note: $\quad * *$ Correlation coefficient is statistically significant at $\mathrm{p}<0.01$.

*Correlation coefficient is statistically significant at $\mathrm{p}<0.05$.

${ }^{6}$ Factors as reported by Pittam et al. (2009) 
Table 2

Exploratory Factor Analysis: Rotated factor loadings and internal consistency reliability

\begin{tabular}{|c|c|c|c|c|}
\hline \multirow{2}{*}{$\begin{array}{l}\text { SAC } \\
\text { Item }\end{array}$} & & \multicolumn{3}{|c|}{ Factor } \\
\hline & & 1 & 2 & 3 \\
\hline \multicolumn{5}{|c|}{$(\alpha=0.71)$} \\
\hline 1 & $\begin{array}{l}\text { I know what it means to be the author of a piece of written } \\
\text { work }\end{array}$ & 0.68 & & \\
\hline 2 & I know what the responsibilities of an author are & 0.73 & & \\
\hline 3 & I would never be accused of plagiarism & 0.63 & & \\
\hline 4 & $\begin{array}{l}\text { I know how to provide references for citations and quotations } \\
\text { in my written work }\end{array}$ & 0.67 & & \\
\hline 8 & $\begin{array}{l}\text { I know how to show which parts of my assignments were not } \\
\text { written by me }\end{array}$ & 0.60 & & \\
\hline \multicolumn{5}{|c|}{$(\alpha=0.61)$} \\
\hline 6 & $\begin{array}{l}\text { I find it difficult to express my subject (i.e. accounting) in my } \\
\text { own words }\end{array}$ & & 0.68 & \\
\hline 10 & $\begin{array}{l}\text { I just don't have time to put everything in my own words when } \\
\text { writing an assignment }\end{array}$ & & 0.66 & \\
\hline 11 & $\begin{array}{l}\text { I get better marks when I use more material taken directly from } \\
\text { books, journals or the internet in my assignments }\end{array}$ & & 0.59 & \\
\hline 16 & $\begin{array}{l}\text { I am afraid that what I write myself about accounting will look } \\
\text { weak and unimpressive }\end{array}$ & & 0.69 & \\
\hline \multicolumn{5}{|c|}{$(\alpha=0.53)$} \\
\hline 14 & $\begin{array}{l}\text { Writing is all about making an argument based on my thoughts } \\
\text { about the subject }\end{array}$ & & & 0.66 \\
\hline 15 & $\begin{array}{l}\text { I am confident that when I write something about accounting it } \\
\text { will look impressive }\end{array}$ & & & 0.71 \\
\hline 17 & $\begin{array}{l}\text { I get higher marks by writing more of my assignment in my } \\
\text { own words }\end{array}$ & & & 0.58 \\
\hline
\end{tabular}

Note: Factor loadings lower than 0.5 are not shown. 
Table 3: Panel A

CFA goodness-of-fit statistics $(N=588)$ and factor correlations

\begin{tabular}{|c|c|c|c|c|c|c|}
\hline \multicolumn{2}{|r|}{ Model } & \multirow{2}{*}{$\frac{\chi^{2}}{476.315}$} & \multirow{2}{*}{$\frac{d . f .}{120}$} & \multirow{2}{*}{$\frac{C F I}{0.787}$} & \multirow{2}{*}{$\begin{array}{c}\text { RMSEA } \\
0.071\end{array}$} & \multirow{2}{*}{$\begin{array}{c}\text { SRMR } \\
0.067\end{array}$} \\
\hline I & Six factors & & & & & \\
\hline II & Two factors & 786.355 & 134 & 0.609 & 0.091 & 0.087 \\
\hline III & One factor & 839.214 & 135 & 0.578 & 0.094 & 0.085 \\
\hline IV & Three factors & 136.643 & 47 & 0.924 & 0.057 & 0.051 \\
\hline
\end{tabular}

Table 3: Panel B

Factor correlations in Model IV

\begin{tabular}{lccccc} 
& Alpha & Mean & Std. Dev. & Factor 1 & Factor 2 \\
Factor 1 & 0.71 & 3.92 & 0.61 & & \\
Factor 2 & 0.61 & 3.05 & 0.70 & $-0.27^{* * *}$ & \\
Factor 3 & 0.53 & 3.29 & 0.65 & $0.48^{* * *}$ & $-0.53^{* * *}$ \\
\hline
\end{tabular}

Note: ${ }^{* * *} p<0.001$

Factor 1: Understanding authorship and plagiarism

Factor 2: Lack of confidence in writing

Factor 3: Authorial approach to writing 
Figure 1: The revised model

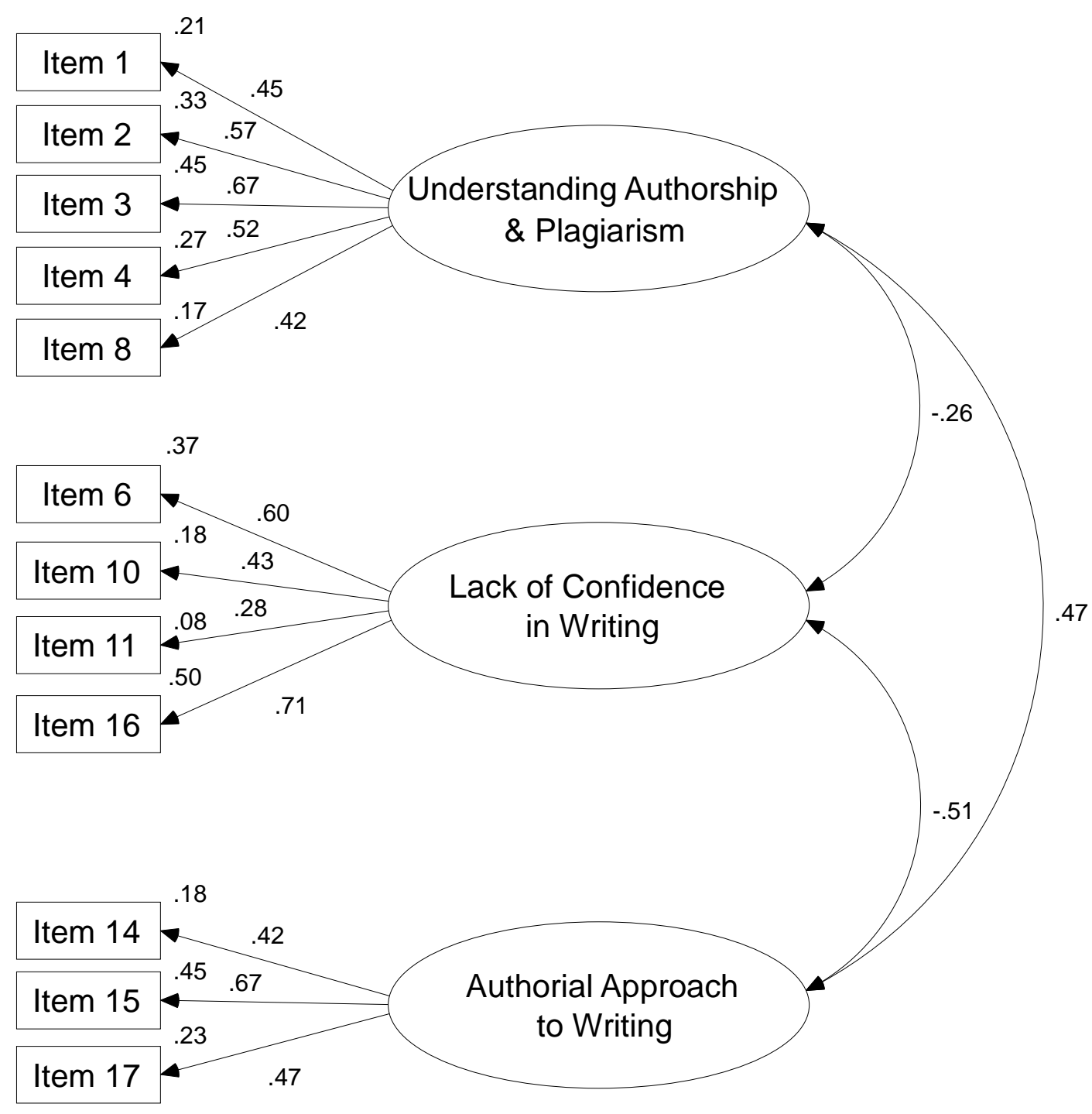

